\title{
İlköğretim Okullarında Uygulanan Mesleki Çalışmalarda Yaratıcı Drama Uygulamasının Öğretmenlerin İletişim Becerilerine Etkisi*
}

\author{
Birsen Kılıçaslan Binici ${ }^{1}$
}

\begin{abstract}
$\ddot{O}_{z e t}$
Bu araştırma ile Kartal Milli Ĕgitim Vakfi İlköğretim Okulu’nda mesleki çalışmalar (seminer dönemi) kapsamında iletişim becerileri konusunda yaratıcı drama ve düz anlatım yöntemlerinin etkililiğinin karşılaştırılması amaçlanmıştır. Araştırmada Kartal Milli Ĕgitim Vakfi İlköğretim Okulu öğretmenlerinden toplam 50 öğretmen yer almıştır. Araştırmada veri toplama aracı olarak Ersan ve Balcı tarafindan geliştirilen "Illetişim Becerileri Envanteri” kullanılmıştır. Envanter deney ve kontrol gruplarına program öncesinde ön test olarak uygulanmıştır. Ön test ölçümünün ardından deney grubuna 12 saatten oluşan yaratıcı drama yönteminin ve kontrol grubuna da aynı süreyi kapsayan düz anlatım yönteminin kullanıldĭ̆ iletişim becerileri ĕgitim programı gerçekleşmiştir. Uygulamaların ardından deney ve kontrol gruplarına aynı ölçme aracı son test olarak uygulanmıştır. Verilerle ilgili istatistiksel analizler Windows/SPSS 13.0 programında değerlendirilmiştir. İletişim becerilerini geliştirmeye yönelik eğitimlerde kullanılan yaratıcı drama ve düz anlatım yöntemlerinin etki düzeyini ve etki düzeyleri arasında fark olup olmadığını anlamak için Mann Whitney U Testi ve Wilcoxon Işaretli Sıralar Testi kullanılarak gruplar arasında karşılaştırma yapılmıştır. Yapılan analizler ile iletişim becerileri açısından düz anlatım yöntemi ve yaratıcı drama yöntemi zihinsel, duygusal ve davranışsal boyutlarıyla karşılaştırılmıştır.
\end{abstract}

Anahtar Sözcükler: Mesleki çalışmalar (seminer dönemi), iletişim becerileri, kişilerarası iletişim, yaratıcı drama, düz anlatım.

\begin{abstract}
The aim of the present survey was to compare the effectiveness of "creative drama" and "traditional techniques" used at "Kartal M.E. V. Primary School" during vocational seminars. 50 teachers from "Kartal M.E. V. Primary School" participated in the present study. There were two groups in this survey, namely experimental and control groups. In order to collect the data, "communicative skills inventory" which was developed by Ersan and Balcr was used. This inventory was applied to the "experimental" group and to the "control" group as the pretest before our program. After the assessment of the pretest, the experimental group took an educational program of communicative skills through creative drama techniques for 12 hours, whereas the control group took the same course through traditional techniques. After these applications, the same means of assessment was given once again to both groups of teachers. The analysis related to the data was evaluated by "windows/SPSS 13.0 program. To be able to see the impact and understand the difference between "Creative Drama", and "traditional techniques", which are used to improve the communicative skills during the training sessions, "Mann Whitney U" and "Wilcoxon Marked Desks Test" were used. The analyses revealed that traditional techniques were only effective in terms of mental conditions, whereas creative drama could affect not only the mental conditions, but their emotions and behavioral patterns as well.
\end{abstract}

Keywords: Vocational Studies (Seminar Period), Communication Skills, Interpersonal Communication, Creative Drama, Lecturing.

* Makale sahibinin soyadı bir önceki sayıda yanlış yazıldığı için bu sayıda makaleyi tekrar yayımlıyor, yazarımızdan özür diliyoruz.

1 Öğretmen, Milli Eğitim Bakanlığı, birsenkilicaslan@gmail.com 


\section{Giriş}

Eğitim, yaşam boyu devam eden bir süreçtir. Bu süreçteki gelişmelere ve değişimlere bağlı olarak öğretmenler, gelenekselleşmiş öğretim yöntemlerinin yanı sıra, ihtiyaca cevap veren alternatif öğretim yöntemlerini de kullanan, aktaran, çağdaş eğitim perspektifi içerisinde yenilikçi, yaratıcı, iletişime açık bireyler olmak zorundadırlar. Mesleki bilgilerin gelişmelere bağlı olarak hızla eskimesi, kişilerarası iletişimin öneminin artması, mesleki çalışmaların gerekliliğini daha da açığa çıkarmaktadır.

Öğretmenlik mesleği; eğitim sektörü ile ilgili olan sosyal, kültürel, ekonomik, bilimsel ve teknolojik boyutlara sahip, alanda özel uzmanlık bilgi ve becerisini temel alan akademik çalışma ve mesleki formasyonu gerektiren, profesyonel statüde bir uğraş alanıdır (Alkan ve Hacığlu, 1995: 23-24). Öğretmenlik, niteliği ve işlevi bakımından, toplumun sosyal ve kültürel gelişiminde son derece önemli bir meslektir. Öğretmenlik mesleğinin kalitesinin arttırılması, öğretmenlerin sahip olması gereken genel ve özel alan yeterliklerin bilinmesi, daha sonra da bu yeterliklerin, mesleki çalışmalar kapsamında gerçekleştirilebilecek eğitimlerle öğretmenlere kazandırılması mümkündür.

Öğretmenin hoşgörülü, sabırlı, sevecen, kendini geliştirmeye eğilimli, planlı, sistemli, değişikliklere uyum sağlayabilen, koruyucu destekleyici, yönlendirici, samimi, etkin iletişim becerilerine sahip olması gerektiği sıkça vurgulanmaktadır. Anılan bu özellikler öğretmenin kişisel eğilimiyle ve gelişimiyle ilgilidir (Karadağ, 2005: 22). Öğretmen kendini geliştirdiği ölçüde kendisini, insanları ve çevresini olumlu etkiler. Bu etkiyi sağlayan öğrenme yöntemlerinden bir tanesi de yaratıcı drama yöntemidir.

Mesleki çalışma, ilköğretim okullarında görevli yönetici ve öğretmenlerin genel kültür, özel alan ve pedagojik formasyon alanlarında bilgi ve görgülerini artırmak, yeni beceriler kazandırmak, eğitim-öğretimde karşılaşılan problemlere çözüm yolları bulmak, öğrencinin ve çevrenin ihtiyaçlarına göre plan ve programları hazırlamak ve uygulamak amacıyla derslerin bitiminden Temmuz ayının ilk iş gününe; Eylül ayının ilk iş gününden derslerin başlangıcına kadar, yıl içinde ise yıllık çalışma programında belirtilen sürelerde yapılan çalışmalardır (MEB, 2003). Bu çalışmaların hedef kitlesi öncelikle öğretmenlerdir.

Yaratıcı dramanın amacı da bireysel üretkenliği toplumsal üretkenliğe dönüştürmektir. Birey içindeki enerjinin, gücün farkına varıp onu ortaya çıkaracak, böylece toplumsal yaşam içerisinde daha aktif daha verimli bir rol üstlenecektir. Yapılan kimi tanımlardan da bunu anlayabiliyoruz: "Bir lider ister dramayı bir yöntem olarak dersi aktif hale getirebilmeyi, isterse bir disiplin olarak saklı enerjiyi ortaya çıkarıp bireyin her yönden gelişmesi ve yaratıcı kılmasını amaçlasın, amacı diğer disiplinler gibi çocuğu ve ergeni yaşama hazır hale getirip onu olgunlaştırmaktır” (Adıgüzel, 2002: 213).

Öğrenme süreci belli bir yaş diliminde yapılıp bitirilen, belli bir sürede sonuçlanan bir olgu değildir. Buna göre yaratıcı dramanın bir yöntem olması ve bu özelliği ile öğrenme-öğretme yaşantılarının paylaşılmasındaki yeri kolaylıkla anlaşılabilir. Yaratıcı dramanın bir öğrenme yolu olarak en önemli varlığı; düşünsel, duygusal ve bedensel boyutlarıyla bütünleşmiş olmasıdır. Her öğrenme biçiminde bulunan pek çok beceri yaratıcı dramaya katılım yoluyla elde edilir. Bu özelliği ile yaratıcı dramanın kişiler arasındaki ilişkilerle bir arada yorumlanabilecek yönü bulunmaktadır (Üstündağ, 2006: 24-25).

Yaratıcı dramada birey, farkında olmadan bir yandan duyularını eğitme sürecinde, diğer yandan da öğrenme sürecinde etkin katılımcıdır. Kişi kendi yaptığıyla öğrenirken duyu organlarını harekete geçirir ve unutulmayacak yaşantılar kazanır. Bu yaşantıların kazanılması aynı zamanda, bireyin sözel ve sözel olmayan iletişim becerilerini de geliştirmesi demektir (Üstündağ, 2006: 27). Yaratıcı drama iletişim becerilerini, yaratıcılığ1 geliştiren etkili bir yöntem ve yaratıcı bireyi yetiştiren başlı başına bir öğrenme-öğretme alanıdır. 
Yaratıcı dramada, iletişim süreci içindeki sözsüz davranış, kişiler arasındaki iletişim akışını düzenlemektedir. Sözsüz davranışlar birçok zaman iletişim sürecinin başlamasını ve devam etmesini sağlamakta, etkileşimcilerin geribildirimi alarak sağlıklı iletişimi mümkün kılmaktadır.

Yaratıcı dramada birey doğaçlama, rol oynama vb. tekniklerle değişik rollere bürünürken gerçekleştirdiği sözel oluşumlar sırasında; gülümseme, sıkıntı, sinirlilik, mutluluk, vb. yüz ve göz iletişimini sağladığı etkinlikler hemen her paylaşımında yer alır. Duyuları kullanmayı öğrenme yaratıcı dramanın en önemli konularından biridir. Yaratıcı drama etkinliklerinde, özellikle dokunma duyusunun kullanımıyla ilgili pek çok yaşantı söz konusudur. Alan kullanımı, bedenin rahat bir görünüm alması, duruş, elleri, kolları ve bacakları kullanma, giysi, aksesuar seçme gibi sözel olmayan iletişimle ilgili ipuçları yine bu süreçte fazlasıyla yer alır" (Üstündağ, 2007: 34).

Drama süreçlerinde kişiler etkinlikler kapsamında birbirinden farklı rolleri üstlenirler. Bu roller onların farklı "konuşma, dinleme, yazma, ve okuma" dilini kullanmalarının bir örneği olarak verilebilir. Bu rollerin üstlenilmesi sırasında kişilerin yaşadığı çeşitli duygular, tutumlar, güdülenme düzeyleri vd. duygusal davranışlar da kişilerin bir yandan dil kullanma becerileri geliştirirken diğer yandan iç dünyalarını zenginleştirir. Kişiler; olaylar, durumlar, neden sonuç ilişkileri vd. açılardan irdelemeler yaparken sorun çözme güçlerini de geliştirirler. $\mathrm{Bu}$ yolla yargılama ve değerlendirme yetilerini besleyerek eleştirel düşünme alışkanlığı kazanırlar. Yaratıcı dramada ele alınan öykü, masal, şiir, anı, makale vd. edebiyat ürünlerinin incelenmesiyle sanatsal ve estetik değerlerin gösterilmesiyle öğrenenlerin imgelem gücü zenginleşir (Üstündağ, 2007: 31).

Drama, kişilerin hem birbirleriyle konuşmalarını gerçekleştirdikleri "sosyal dil”i hem de kendi kendileriyle gerçekleştirdikleri "iç dil”"i geliştirme olanağ1 sağlar. Ses, tempo, vurgu, söyleyiş başka hiçbir konuşma formunda olmadığı kadar doğal bir biçimde drama sürecinde kullanılır ve gelişir (Tuğrul, 2003: 121138).

Gordon'a (1997) göre etkin dinleme, öğrenilebilecek en önemli iletişim becerilerinden biridir. Etkin dinlemede mesajı alan kişi gönderen kadar etkin olmaktadır. Mesajı alan kişi, öncelikle gönderenin duygularını ve mesajın ne anlama geldiğini anlamaya çalışmakta, daha sonra anladıklarının doğruluğunu sınamak için, kendi sözcükleri ile gönderene iletmektedir. Yaratıcı drama sürecinde grup çalışmaları esnasında etkin dinleme becerisini geliştirmek mümkündür. "Bireylerin sıcak ilişkiler geliştirmesine yardım etmektedir. Çünkü anlaşılmak bireylerde olumlu duygular yaratmakta ve dinleyiciye yakınlık duyulmasına neden olmaktadır" (Cihangir, 2004: 44).

Drama sürecindeki dinamizm, kişileri etkin kılar. Kişiler, yaratıcı drama sürecinde konuşurlar, hareket ederler, bedenlerini, seslerini, duygularını, düşüncelerini kullanırlar, başkalarıyla iletişim içinde olurlar, kendi kendilerine kalarak düşünme olanağı bulurlar, özgün düşünce, davranış ve somut ürün oluştururlar, simgeler kullanırlar, hayal kurarlar, eğlenir ve mutlu olurlar (Tuğrul, 2003: 121-138). Kişinin yaparak ve yaşayarak geçirdiği yaratıcı drama sürecinde engellerin var olması bu sürece aykırı bir durumdur. Yaratıcı dramada kurallar vardır ancak engeller yoktur.

\section{Çalışmanın Amacı}

$\mathrm{Bu}$ araştırmanın amacı; resmi ilköğretim okullarında mesleki çalışmalar (seminer dönemi) kapsamında iletişim becerileri açısından yaratıcı drama yöntemi ile eğitim alan öğretmenler ile düz anlatım yöntemiyle eğitim alan öğretmenler arasındaki farklılıkları ortaya koyabilmek ve gerekli çözüm önerilerini bilimsel temellere göre geliştirebilmektir. 


\section{Yöntem}

$\mathrm{Bu}$ araştırmada gerçek deneme modellerinden "Ön test - son test kontrol gruplu model” kullanılmıştır. "Öntest - sontest kontrol gruplu modelde, yansız atama ile oluşturulmuş iki grup bulunur. Bunlardan biri deney, öteki kontrol grubu olarak kullanılır. Her iki grupta da deney öncesi ve deney sonrası ölçmeler yapılır” (Karasar, 2003: 97).

Tablo 1. Deney Deseni

\begin{tabular}{|c|c|c|c|}
\hline Grubun Adı & Deney Öncesi & Deney Süreci & Deney Sonrası \\
\hline Deney Grubu & $\begin{array}{c}\text { Öntest } \\
\text { (İletişim Becerileri Envanteri) }\end{array}$ & $\begin{array}{c}\text { Yaratıcı Drama Yöntemi ile } \\
\text { Öğretim Süreci }\end{array}$ & $\begin{array}{c}\text { Sontest } \\
\text { (Illetişim Becerileri } \\
\text { Envanteri) }\end{array}$ \\
\hline Kontrol Grubu & $\begin{array}{c}\text { Öntest } \\
\text { (İletişim Becerileri Envanteri) }\end{array}$ & $\begin{array}{c}\text { Düz Anlatım Yöntemi ile } \\
\text { Öğretim Süreci }\end{array}$ & $\begin{array}{c}\text { Sontest } \\
\text { (İletişim Becerileri } \\
\text { Envanteri) }\end{array}$ \\
\hline
\end{tabular}

Araştırmada veri toplama aracı olarak Ersan ve Balcı tarafından geliştirilen “İletişim Becerileri Envanteri” kullanılmıştır. Ersan ve Balcı tarafından geliştirilen İBE, test yarılama yöntemiyle yapılan güvenirlik çalışması sonucunda güvenirlik katsayıs1 .64, test - tekrar sonucunda güvenirlik katsayıs1 .68 olarak bulunmuştur. Ölçeğin iç tutarlı̆̆ını belirlemek amacıyla hesaplanan Cronbach alpha katsayısı ise, .72 olarak bulunmuştur. Bu bulgular, ölçeğin güvenirliliğinin kullanılabilir düzeyde olduğunu göstermektedir. Ersan ve Balcı (1998) tarafından son hali verilen envanter, likert tipi 45 sorudan oluşmaktadır. Derecelendirme şu şekildedir; Hiçbir zaman (1), Nadiren (2), Bazen (3), Genellikle (4), Her zaman (5) anlamına gelmektedir. Envanter, zihinsel, duygusal ve davranışsal açıdan iletişim becerilerini ölçmektedir.

Envanterin 1, 3, 6, 12, 15, 17, 18, 20, 24, 28, 30, 33, 37, 43, 45. soruları iletişim becerileri zihinsel alt boyutunu, 5, 9, 11, 26, 27, 29, 31, 34, 35, 36, 38, 39, 40, 42, 44. soruları iletişim becerileri duygusal alt boyutunu, 2, 4, 7, 8, 10, 13, 14, 16, 19, 21, 22, 23, 25, 32, 41. soruları iletişim becerileri davranışsal alt boyutunu ölçmektedir.

Envanter deney ve kontrol gruplarına program öncesinde ön test olarak uygulanmıştır. Ön test ölçümünün ardından deney grubuna 12 saatten oluşan yaratıcı drama yönteminin kullanıldığı iletişim becerileri eğitim programı ve kontrol grubuna da aynı süreyi kapsayan düz anlatım yönteminin kullanıldığı iletişim becerileri eğitim programı gerçekleştirilmiştir. Uygulamaların ardından deney ve kontrol gruplarına aynı ölçme aracı (İBE) son test olarak uygulanmıştır. İletişim becerilerini geliştirmeye yönelik eğitimlerde kullanılan yaratıcı drama ve düz anlatım yöntemlerinin etki düzeyini ve fark olup olmadığını anlamak için Mann Whitney U Testi ve Wilcoxon İşaretli Sıralar Testi kullanılarak gruplar arasında karşılaştırma yapılmıştır.

\section{Çalışma Grubu}

Bu araştırmada 2009-2010 eğitim - öğretim yılında, İstanbul ili Kartal İlçesi Kartal Milli Eğitim Vakfı İlköğretim Okulu'nda gerçekleşmiştir. Araştırmanın yapılabilmesi için ilgili okuldan izin alınmıştır. Araştırmada görev yapan 50 öğretmen gönüllü olarak yer almıştır. Deney ve kontrol gruplarının her birinde 25 öğretmen katılımc1 bulunmaktadır. 


\section{Bulgular}

Tablo 2. Illetişim Becerilerinin Zihinsel Alt Boyutunun Deney ve Kontrol Grubuna İlişkin Mann-Whitney U Testi Sописи

\begin{tabular}{|c|c|c|c|c|c|c|c|}
\hline & $\mathrm{N}$ & $\begin{array}{c}\text { Sira } \\
\text { Ortalaması }\end{array}$ & $\begin{array}{c}\text { Sira } \\
\text { Toplamu }\end{array}$ & $\begin{array}{c}\text { Mann- } \\
\text { Whitney U }\end{array}$ & $\begin{array}{c}\text { Wilcoxon } \\
\text { W }\end{array}$ & Z & P \\
\cline { 1 - 4 } $\begin{array}{c}\text { Düz } \\
\text { Anlatım }\end{array}$ & 25 & 20,30 & 507,50 & & & & \\
\cline { 1 - 4 } $\begin{array}{c}\text { Yaratıcı } \\
\text { Drama }\end{array}$ & 25 & 30,70 & 767,50 & 182.500 & 507,500 & $-2,527$ & 0.011 \\
\hline Toplam & 50 & & & & & \\
\hline
\end{tabular}

Analiz sonuçları, yaratıcı drama yöntemi ve düz anlatım yöntemi ile eğitim alan öğretmenlerin iletişim becerileri envanterinin zihinsel alt boyutu testinden aldıkları puanlar arasında anlamlı bir fark olduğunu göstermektedir $(U=182,5, \mathrm{p}<.05)$. Sira ortalamaları dikkate alındığında yaratıcı drama yöntemi ile eğitim alan öğretmenlerin düz anlatım yöntemi ile eğitim alan öğretmenlere göre iletişim becerileri envanterinin zihinsel alt boyutundan aldıkları puanın daha yüksek olduğu anlaşılmaktadır. Bu bulgu, yaratıcı drama yönteminin iletişim becerilerinin zihinsel alt boyutunun geliştirilmesinde daha etkili olduğunu göstermektedir.

Tablo 3. Illetişim Becerilerinin Duygusal Alt Boyutunun Deney ve Kontrol Grubuna İlişkin Mann-Whitney U Testi Sописи

\begin{tabular}{|c|c|c|c|c|c|c|c|}
\hline & $\mathrm{N}$ & $\begin{array}{c}\text { Sira } \\
\text { Ortalamas1 }\end{array}$ & $\begin{array}{c}\text { Sira } \\
\text { Toplamu }\end{array}$ & $\begin{array}{c}\text { Mann- } \\
\text { Whitney U }\end{array}$ & $\begin{array}{c}\text { Wilcoxon } \\
\text { W }\end{array}$ & Z & $\mathrm{P}$ \\
\hline $\begin{array}{c}\text { Düz } \\
\text { Anlatım }\end{array}$ & 25 & 21,10 & 527,50 & \multirow{3}{*}{202.500} & \multirow{3}{*}{527,500} & \multirow{3}{*}{$-2,140$} & \multirow{3}{*}{0.032} \\
\hline $\begin{array}{l}\text { Yaratic1 } \\
\text { Drama }\end{array}$ & 25 & 29.90 & 747,50 & & & & \\
\hline Toplam & 50 & & & & & & \\
\hline
\end{tabular}

Analiz sonuçları, yaratıcı drama yöntemi ve düz anlatım yöntemi ile eğitim alan öğretmenlerin iletişim becerileri envanterinin duygusal alt boyutu testinden aldıkları puanlar arasında anlamlı bir fark olduğunu göstermektedir $(U=202,5, \mathrm{p}<.05)$. Sira ortalamaları dikkate alındığında yaratıcı drama yöntemi ile eğitim alan öğretmenlerin düz anlatım yöntemi ile eğitim alan öğretmenlere göre iletişim becerileri envanterinin duygusal alt boyutundan aldıkları puanın daha yüksek olduğu anlaşılmaktadır. Bu bulgu yaratıcı drama yönteminin iletişim becerilerinin duygusal alt boyutunun geliştirilmesinde daha etkili olduğunu göstermektedir. 
Tablo 4. Iletişsim Becerilerinin Davranışsal Alt Boyutunun Deney ve Kontrol Grubuna İlişkin Mann- Whitney U Testi Sonucu

\begin{tabular}{|c|c|c|c|c|c|c|c|}
\hline & $\mathrm{N}$ & $\begin{array}{c}\text { Sira } \\
\text { Ortalamas1 }\end{array}$ & $\begin{array}{c}\text { Sira } \\
\text { Toplamu }\end{array}$ & $\begin{array}{c}\text { Mann- } \\
\text { Whitney U }\end{array}$ & $\begin{array}{c}\text { Wilcoxon } \\
\text { W }\end{array}$ & Z & P \\
\cline { 1 - 3 } $\begin{array}{c}\text { Düz } \\
\text { Anlatım }\end{array}$ & 25 & 22,34 & 558,50 & & & & \\
\cline { 1 - 3 } $\begin{array}{c}\text { Yaratıc1 } \\
\text { Drama }\end{array}$ & 25 & 28,66 & 716,50 & 233.500 & 558,500 & $-1,539$ & 0.124 \\
\cline { 1 - 3 } Toplam & 50 & & & & & & \\
\hline
\end{tabular}

Analiz sonuçları, yaratıcı drama yöntemi ve düz anlatım yöntemi ile eğitim alan öğretmenlerin iletişim becerileri envanterinin davranışsal alt boyutu testinden aldıkları puanlar arasında anlamlı bir fark olduğunu göstermektedir $(\mathrm{U}=233,5, \mathrm{p}<.05)$. Sıra ortalamaları dikkate alındığında, yaratıcı drama yöntemi ile eğitim alan öğretmenlerin düz anlatım yöntemi ile eğitim alan öğretmenlere göre iletişim becerileri envanterinin davranışsal alt boyutundan aldıkları puanın daha yüksek olduğu anlaşılmaktadır. Bu bulgu yaratıcı drama yönteminin iletişim becerilerinin davranışsal alt boyutunun geliştirilmesinde daha etkili olduğunu göstermektedir.

\section{Sonuç}

Çalışmayı gerçekleştirdiğimiz Kartal Milli Eğitim Vakfı İlköğretim Okulu öğretmenlerinin birçoğunun, geleneksel yaşam biçiminin belirleyici olduğu kültürel ortamlarda yetiştiği ve o kültürün kendilerine sunduğu eğitim ile büyüdükleri söylenebilir. Bu öğretmenlerin önemli bir kısmının kendini ifade etme, yeteneklerini farkına varma, yaratıcılığını ortaya koyma, grup karşısında konuşma gibi bazı güçlüklerle karşılaştıkları gözlemlenmektedir. Öğretmenler yaratıcı dramanın bu sıkıntıları gidermede ne kadar etkili olduğunu yaşayarak öğrenmektedir.

İlköğretim okullarında uygulanan mesleki çalışmalarda (seminer dönemi) yaratıcı drama uygulamasının, öğretmenlerin iletişim becerilerine etkisinin araştırıldığ bu araştırmada elde edilen sonuçlar şunlardır:

Bireyin zihinsel gelişimi onun hem doğuştan getirdiği zihin gücüne, hem çevresiyle etkileşimi, hem de zaman sonucunda edindiği yaşantılarına dayanmaktadır. Yaşamın kendisi öğrenme için en uygun, en zengin ve en doğal deneysel ortamdır. Gerçek yaşam deneyimlerinden soyutlanmış, bireyin gereksinimleriyle uyuşmayan suni öğrenme ortamları bireyin gelişimi için uygun ortamlar değildir. Yaratıcı drama, zekânın çok boyutlu kapasitesini kullanma ve geliştirme olanağı sunar. Bulgulardan da anlaşıldığı gibi, öğrenmenin daha kalıcı olduğu yaratıc drama yöntemi ile verilen eğitimin, öğretmenlerin iletişim becerilerinin zihinsel alt boyutunun geliştirilmesinde etkili olduğu görülmüştür. Düz anlatım yöntemi ile gerçekleştirilen ortamlarda gerçek yaşam deneyimleri dikkate alınmaz. Zekânın çok boyutlu kapasitesini kullanma ve geliştirme olanağı yoktur. Buna karş111k öğretmenin tamamen etkin ve merkezde olduğu bu yöntemde öğrenci adına bir katılım yoktur. Düz anlatım yöntemi ile verilen eğitim, öğretmenlerin iletişim becerilerinin sadece zihinsel alt boyutunun geliştirilmesinde etkili olmuştur.

Herhangi bir şey üzerine bir şeyler düşünebilmek ya da herhangi bir şey/olay ya da durum üzerine bir şeyler hissetmek önemlidir. Uygun ve kabul edilebilir kanallar aracılığıyla güçlü duyguların ve düşüncelerin 
dışarıya aktarılması, paylaşılması gerekir. Her birey değişik zamanlarda değişik duygular hissedebilir. Duygu ve düşüncelerin yansıtılmasına olanak tanıyan yaratıcı drama yöntemi ile verilen eğitim, öğretmenlerin iletişim becerilerinin duygusal alt boyutunun geliştirilmesinde etkili olduğu görülmüştür. Buna karş1lık düz anlatım yöntemi ile gerçekleştirilen bir öğretim sürecinde birey, duygu ve düşüncelerini aktarmaz ve paylaşımda bulunmaz, pasif dinleyici konumundadır. Araştırmada elde edilen bulgular düz anlatım yöntemi ile verilen eğitim, öğretmenlerin iletişim becerilerinin duygusal alt boyutunun geliştirilmesinde etkili olmadığını ortaya koymaktadır.

Birey, yaparak ve yaşayarak öğrenmenin gerçekleştiği yaratıcı drama sürecinde etkindir. Sürece tüm duyu organları etkin bir şekilde dahil edilir. Birey, etkin olduğu süreci davranışlarına yansıtır ve süreci daha anlamlı kılar. Bu çalışmanın bulguları, yaratıcı drama yöntemi ile verilen eğitimin öğretmenlerin iletişim becerilerinin davranışsal alt boyutunun geliştirilmesinde etkili olduğunu ortaya koymuştur. Buna karşıllk düz anlatım yönteminde sadece görerek ve duyarak öğrenme gerçekleşir. Diğer duyu organları öğrenme sırasında aktif değildir. Yaparak ve yaşayarak öğrenmenin gerçekleşmediği düz anlatım yöntemi ile verilen eğitim, öğretmenlerin iletişim becerilerinin davranışsal alt boyutunun geliştirilmesinde istenildiği kadar etkili olmadığ görülmüştür.

\section{Kaynaklar}

Adıgüzel, Ö. H. (2002). Eğitimde Yeni Bir Yöntem ve Disiplin: Yaratıı Drama, Adıgüzel, Ömer H. (Ed.), Yaratıcı Drama (2. Bask1) içinde (203-222). Ankara: Naturel Yayıncılık.

Alkan,C. ve Hacığlu, F. (1995). Öğretmenlik Uygulamaları. İstanbul: Alkın Yayınevi.

Balcı, S. ve Ersanlı, K. (2006). İletişim Becerileri Envanterinin Geliştirilmesi: Geçerlik ve Güvenirlik Çalışması, Türk Psikolog Danışma ve Rehberlik Dergisi, 2,10. 7-12.

Cihangir, Z. (2004). Kişilerarası İletişimde Dinleme Becerisi. Ankara: Nobel Yayın Dağıtım.

Gordon, T (1997). Etkili Anababa Eğitimi (3. Baskı). (çev. Aksay, E). İstanbul: Sistem Yayıncılık.

Karadağ, E. (2005). Eğitim Yönetimi ve Öğretim Yöntemleri İlişkisi Kapsamında Drama Yönteminin Değerlendirilmesi. Yayımlanmamış Yüksek Lisans Tezi, Yeditepe Üniversitesi.

Karasar, N. (2003). Bilimsel Araştırma Yöntemi (12. Baskı). Ankara: Nobel Yayın Dağıtım.

Anonim: Milli Eğitim Bakanlığı, İlköğretim Kurumları Yönetmeliği, 25212 sayıl1/ 27.08.2003 Resmi Gazete.

Tuğrul, B. (2003). Drama ve Öğrenme- Öğretme. Öztürk, A. (Ed.), Çocukta Yaratıcılık ve Drama içinde (121-138). Eskişehir: Anadolu Üniversitesi Yayınları.

Üstündağ, T. (2006). Yaratıı Drama Öğretmenimin Günlüğü (7. Baskı). Ankara: PegemA Yayıncılık.

Üstündağ, T. (2007). İletişim Sürecinde Yaratıı Drama. Aslan, N. (Ed.), Dramaya Çok Yönlü Bakış içinde (29-35). Ankara: Oluşum Yayınları. 


\title{
Summary
}

\section{The Effect Of Creative Drama Practices Durıng Vocational Studies (Semınar Perıd) On The Communucation Skills Of Teachers In Primary Schools}

\author{
Birsen Kılıçaslan Binici²
}

\section{Introduction}

Education is a lifelong process. Depending on the improvements and changes during this process, in addition to traditional teaching methods (techniques), teachers have to be individuals who can use alternative teaching techniques and convey (transfer) them to their students. Moreover, they have to be innovative and open to communication in the light of contemporary education. The fact that professional knowledge wears out so quickly due to the developments, it is obviously essential to give emphasis on professional studies and follow the innovations due to the increasing importance of interpersonal communication.

Teaching, in terms of the nature and function of society is an extremely important social and cultural development of the profession. Improving the quality of the teaching profession, teachers must possess the general and specific competences, knowledge and later, the qualifications, training teachers to gain professional work can be performed within the scope.

Teacher, tolerant, patient, loving, prone to self-development, a planned, systematic, capable of adapting to changes, protective supportive, yönlendirirci, friendly, effective communication skills should be emphasized frequently. And the development of these features on the teacher's personal penchant for the aforementioned (Montenegro, 2005: 22). The teacher, which leads to self-developed, positive impact on people and the environment. One of the drama that this effect, a method of learning methods.

The aim is to convert the individual productivity of social productivity of creative drama. The individual in the energy, it would be aware of power that can be used, so that in the social life will take a more active role more efficiently. We can understand that some of the descriptions given in the: "A leader lesson or drama as a method to make them active is to be stored as a discipline emerged out of energy and creative development of every aspect of the individual to abdicate purpose, the purpose of child and adolescent life, such as other disciplines, ready for olgunlaştırmaktır would bring “(Adıgüzel, 2002: 213).

Professional work, primary schools and teachers' general manager in charge of culture, the areas of private space and pedagogical formation, increase knowledge and gain experience, acquire new skills, find solutions to problems encountered in training and education, according to the needs of the student and the environment in order to prepare and implement plans and programs of courses section of the first working day of July, beginning of September until the first business day of the course, the year of the annual work program within the time periods specified in the studies (Ministry of Education, 2003). The target audience are teachers first of these studies.

Completed the process of learning whether a certain period of years, resulting in a certain period of time is not a phenomenon. Accordingly, a method of creative drama'nın with the teaching-learning experiences, and this feature can be easily understood Recommendations. Creative drama as a way to learn the most important asset, intellectual, emotional, and physical dimensions is integrated. Each lot of skill in the form of learning is achieved through participation in creative drama. This feature is interpreted together with the creative aspect of the drama is the relationship between people (Üstündağ, 2006: 24-25)

3 Teacher, Ministry Education 


\section{Purpose Of The Study}

The purpose of this research, public primary schools, vocational studies (seminar period) in terms of communication skills within the scope of creative drama with straight narrative with the method of training the teachers received training that reveal differences between teachers and science-based recommendations is to gather the necessary solutions.

\section{Method}

This study models a real trial, "pretest - posttest control-group model" is used. "Pretest - posttest controlgroup model, the neutral assignment is created with the two groups. One of these experiments, the other is used as a control group. In both groups, measurements are made after the pre-test” (Karasar, 2003: 97).

As the research data collection tool developed by Balci Ersan and "Communication Skills Inventory" was used. . Ersan and Balci (1998) given by the final version of the inventory, a Likert-type consists of 45 questions. Ratings are as follows: Never (1), Rarely (2), Sometimes (3), Often (4), Always (5) means. Inventory, mental, emotional and behavioral aspects of communication skills measures. Inventory of 1, 3, 6, 12, 15, 17, $18,20,24,28,30,33,37,43,45$ questions, communication skills, mental sub-size, 5, 9, 11, 26, 27, 29, 31, $34,35,36,38,39,40,42,44$ communication skills, emotional questions of sub-size, 2, 4, 7, 8, 10, 13, 14, 16, $19,21,22,23,25,32,41$ communication skills, behavioral questions addressed the lower size of the measure. Inventory control and experimental groups prior to the program as a pre-test was applied. 12 hours after the experimental group pre-test measurement of communication skills training program using creative drama method and the control group the same amount of time covering the plain narrative method was used, communication skills training program. Applications, then the same measurement tool in experimental and control groups (HCI) was applied as a post-test. Communication skills training to improve the methods used in the impact of creative drama, and the level of plain narration, and to understand whether there are differences the Mann-Whitney $U$ test and comparisons between groups were made using the Wilcoxon Signed Test Sequences.

\section{Working Group}

In this study of 2009-2010 - in the academic year, the National Education Foundation of Eagle County, Eagle Elementary School in Istanbul province realized. In order to research the school was allowed. 50 more teachers have been involved as volunteers working in the research. Experimental group and control group of 25 teachers constituted the 25 teachers.

\section{Findings}

Results of the analysis, participated in the survey with the lesson of creative drama and communication skills training of the teachers' mental inventory of sub-size test scores show that a significant difference between the $(\mathrm{U}=182.5, \mathrm{p}<.05)$. Given the mean Queue with creative drama education and training of the teachers, the teachers in the lesson mental inventory of communication skills based on their score is higher than the lower size. This finding creative drama method show that more effective communication skills for the mental development of the lower dimension.

Results of the analysis, creative drama in the research and training of the teachers' communication skills with an inventory of the lesson the emotional subscale scores of the test show that a significant difference $(\mathrm{U}=$ 202.5, $\mathrm{p}<.05$ ). Given the mean Queue with creative drama education and training of the teachers, the teachers in the lesson according to the size of the bottom of the emotional communication skills inventory is higher than 
their scores. This finding creative drama method is more effective in the development of communication skills, emotional dimension is lower.

Results of the analysis, creative drama in the research and training of the teachers' communication skills with the lesson of behavioral sub-dimension of the inventory show that a significant difference between test scores $(U=233.5, p<.05)$. Given the mean Queue with creative drama education for teachers who wish to study according to the teachers' communication skills with the lesson of behavioral sub-dimension of the inventory is higher than their scores. This finding creative drama method show that more effective communication skills in the development of behavioral sub-dimensions.

\section{Result and Suggestions}

National Education Foundation of Eagle Elementary School made the work of many teachers, the traditional way of life is the decisive cultural environments grow and grow up with that culture can be said of education offered to them. This is an important part of teachers' self-expression, awareness skills, creativity, manifestation, such as speaking in front of the group observed that some of the challenges they face. Creative drama to resolve these problems, teachers are learning how effective living. In primary schools, the vocational studies (seminar period) the application of creative drama, the results obtained in this study investigating the effect of teachers' communication skills are as follows:

Both the innate power of his mind brought by an individual's mental development, and interaction with the environment, as well as lives are based on his time as a result. Life itself is the most suitable for learning, the richest and most natural experimental environment. Abstracted from real life experiences, incompatible with the requirements of the individual is not a suitable environment for the development of artificial learning environments of the individual. Creative drama, offers to use and develop the capacity of multi-dimensional intelligence. As is clear from findings, learning is more permanent method of creative drama education provided by teachers in the development of communication skills, cognitive sub-dimension has been effective. Lecture method in real-life experiences of the environment are ignored. Intelligence is not possible to use and develop the capacity of multi-dimensional. However, the teacher is fully effective and the center of this method, not a name of the student. Lecture given by the method of education, teachers' communication skills have been effective only in the development of mental sub-dimension.

Something to think on any thing or any thing / event or situation is important to feel something on. Strong emotions and thoughts through the appropriate and acceptable channels, export, need to share. Feel different emotions at different times in each individual. Reflected the feelings and ideas that allow creative drama education given by teachers in the development of communication skills, emotional sub-dimension has been effective. However, the lesson is a learning process carried out by individuals and share their thoughts and feelings does not pass, is the passive listener. The findings of the research and education in the lesson, the teachers were not effective in the development of communication skills reveals the emotional dimension of the bottom.

The individual, creative drama takes place in the process of learning by doing and experiencing is enabled. Unless you are actively involved in all the sensory organs. The individual, reflects the behavior of the process is effective and makes the process more meaningful. The findings of this study is given to creative drama in education, teachers in developing effective communication skills, behavioral, revealed that the lower size. However, only by seeing and hearing the way learning takes place straight narrative. Other sense organs are not active during learning. Learning by doing and living the lesson to occur, the training, teachers' communication skills in the development of behavioral sub-dimension has not proved effective. 